\title{
Nutrition and platelet function in atherogenesis
}

\section{By John Betteridge, Department of Medicine, University College, The Rayne Institute, University Street, London WC1E 6JJ}

Platelets are undoubtedly involved in the final occlusion of atheromatous arteries forming the major component of the occlusive thrombus (Davies \& Thomas, 1981). This sudden and often catastrophic event is most likely precipitated by fissuring of an atheromatous plaque, as detailed post-mortem analysis of obstructed coronary arteries invariably shows the thrombus in association with plaque haemorrhage (Constantinides, 1966; Davies \& Thomas, 1981). Platelets have also been implicated in cases of sudden cardiac death by the finding of platelet aggregates in the coronary microcirculation (Haerem, 1972; El-Maraghi \& Genton, 1980).

Platelets may also participate in the early stages of atheroma. There is ample evidence, beginning with the work of Duguid (1946), that mural thrombi composed of platelets and fibrin can be incorporated into more advanced lesions (Woolf, 1983). Moreover, the recognition, both in humans and experimental animals, of platelet interactions with the arterial wall at sites which show a predilection for atherosclerosis (Packham \& Mustard, 1986) and of the platelet production of powerful smooth-muscle-cell mitogens such as platelet-derived growth factor (Ross et al. 1974) has focused attention on arterial endothelial-cell damage, platelet adhesion and aggregation and release of mitogens as early events in the atherosclerotic process (Ross \& Glomset, 1976).

In the response-to-injury hypothesis, breach of the endothelial barrier would expose subendothelial smooth muscle cells and connective tissue to plasma constituents including lipoproteins, platelets and macrophage-type mononuclear cells (Harker \& Ross, 1979). Platelets would adhere to the injured site, form microthrombi and releașe their granular contents including platelet-derived growth factor which stimulates migration and focal proliferation of intimal and medial smooth muscle cells (Ross \& Vogel, 1978). Subsequently there would be synthesis of collagen, elastin and proteoglycans by smooth muscle cells and intracellular and extracellular lipid accumulation.

Support for this sequence of events has come from animal models of atherosclerosis and studies using cell-culture techniques and caution is necessary in translating these findings to the human situation. However, there does seem to be considerable evidence linking platelets to the development of proliferative arterial lesions following experimental removal of endothelium in animals either mechanically or chemically (Mustard $e t a l$. 1983). In addition the emerging information regarding the properties of the plateletderived growth factor suggests an important role for this mitogen in the atherogenic process (Bowen-Pope \& Ross, 1984). It should be emphasized here that other cells such as monocytes and endothelial cells may secrete cellular mitogens, and macrophage interaction with the vessel wall may be the first demonstrable lesion in experimental atherogenesis (Faggiotto \& Ross, 1984; Faggiotto et al. 1984; Ross et al. 1984).

Support for the possible role of platelets in atherogenesis is not available from large-scale epidemiological studies which have implicated the traditional risk factors such as hypertension, cigarette smoking, hypercholesterolaemia and diabetes mellitus. This is because there is no entirely satisfactory test of platelet function and those tests that are available would be difficult to apply to the study of large population groups. Nevertheless there is some circumstantial epidemiological evidence linking platelets to atherogenesis stemming mainly from observations of the Greenland Eskimos. 
Eskimos are known to have a markedly reduced risk of myocardial infarction compared with Scandinavian populations (Kromann \& Green, 1980). This has been linked not only to favourable patterns of plasma lipids and lipoproteins but also to the prolonged bleeding time and decreased platelet function observed in Eskimos (Christensen et al. 1953; Bang et al. 1971; Bang \& Dyerberg, 1972). It has been suggested that the prolonged bleeding time is related to changes in the polyunsaturated fatty acid composition of platelet membranes secondary to a high intake of $\omega 3$ fatty acids, particularly eicosapentaenoic acid (20:5w3); this leads to alterations in the platelet prostaglandin pathway and platelet function (Dyerberg et al. 1978). Similar observations have also been made in Japanese fishermen who consume large quantities of fish, this group showing decreased platelet sensitivity to aggregating agents compared with a control group of Japanese farmers (Hirai et al. 1980).

Other circumstantial evidence linking platelets to atherogenesis has come from studies of populations at risk from premature vascular disease, particularly those with hyperlipoproteinaemia and diabetes mellitus. Platelet function has been found to be enhanced in these conditions and may contribute to the development of vascular disease. In the present communication I will review the evidence for enhanced platelet function in hyperlipoproteinaemia and diabetes mellitus, two conditions which have important nutritional implications both in their aetiology and treatment.

An important part of the dietary therapy of both conditions involves a reduction in the amount of saturated fat with substitution of polyunsaturated fatty acids. In view of the Eskimo and Japanese experience in relation to the intake of $\omega 3$ fatty acids and platelet function, I will review the studies which have reproduced this type of diet, and point out the relevance of these studies to the dietary therapy of diabetes mellitus and hyperlipoproteinaemia.

\section{Platelet function in diabetes mellitus}

The increased incidence of atherosclerosis-related disease in diabetes has not been fully explained in terms of known risk factors (Jarrett et al. 1982). Enhanced platelet function may be an additional factor which may help to explain the increased risk. In addition Colwell et al. (1978) have postulated that platelets may contribute to the specific diabetic microvascular disease. Platelet aggregates have been observed in the retinal circulation in diabetic patients and experimental animals (Bloodworth et al. 1965) and microvascular thrombi have been observed in sural nerve biopsies from diabetics (Timperly et al. 1975) and in patients dying from diabetic ketoacidosis (Timperly et al. 1974). Thrombi have been observed in the retinal microvasculature of the experimental diabetic rat some months after the induction of diabetes (Ishibashi et al. 1981).

Platelet studies in diabetes have been reviewed recently (Colwell et al. 1983; Betteridge, 1987) and, despite many research communications, conflicting reports and unresolved questions remain. Perhaps the ideal assessment of platelet activity would be direct observation of platelet-vessel wall interactions but since this is limited to microcirculation studies in animals, less-direct methods have been devised to study platelet behaviour in vitro and the relevance of these tests to in vivo platelet function is uncertain. Platelets are studied in an artificial environment and the preparation of the sample itself may affect platelet behaviour. Despite this the turbidometric method which enables the study of platelet aggregation in vitro (Born, 1962) gave valuable impetus to the subject. This method was used in early studies together with in vitro tests of platelet adhesion which involved the passage of anticoagulated blood through a column containing glass beads or fibres. Differences in the platelet count before and after exposure to these foreign surfaces indicated the number of adherent platelets. The 
majority of studies showed increased adhesion in diabetic subjects with (ValdorfHansen, 1967; Badawi et al. 1970; Mayne et al. 1970; Hellem, 1971) and without (Shaw et al. 1967; Hellem, 1971) vascular disease. However, Heath et al. (1971) did not demonstrate increased adhesion in a group of diabetics with retinopathy.

Studies of in vitro platelet aggregation date from the late 1960s and early 1970s and are difficult to interpret because of imprecise definition of the diabetic populations studied with regard to the presence or absence of vascular complications. If enhanced platelet aggregation were to contribute to the pathogenesis of diabetic vascular disease then evidence of it should be present before the development of vascular disease which itself can lead to changes in platelet behaviour (Ludlam et al. 1975; Handin et al. 1978; Cella et al. 1979; Stewart et al. 1983; Zahavi \& Zahavi, 1985). More recent studies have taken care to define the diabetics studied and the majority of reports of platelet aggregation in diabetics without vascular complications have found increased aggregation to various agonists, particularly ADP and collagen (Sagel et al. 1975; Halushka et al. 1977, 1981a; Stuart et al. 1979; Silberbauer et al. 1981; Janka et al. 1983). However, the occasional study has failed to demonstrate increased aggregation (Petersen \& Gormsen, 1978; Corbella et al. 1979).

'Spontaneous' platelet aggregation has been assessed in diabetics utilizing the platelet:aggregate ratio described by Wu \& Hoak (1974). This depends on the ratio of the platelet count performed on platelet-rich plasma derived from a blood sample taken with and without formalin. Platelet aggregates are fixed by formalin and are removed during centrifugation to produce platelet-rich plasma. The platelet:aggregate ratio is therefore low in the presence of platelet aggregates. Blood-sampling technique is an important variable in this method. Low platelet:aggregate ratios have been found both in diabetics with (Preston et al. 1978) and without (Davis et al. 1982) vascular disease. 'Spontaneous' aggregation has also been studied in platelet-rich plasma or whole blood in vitro using a variety of techniques, mostly involving agitation by stirring. The aggregates formed in this way are fixed by formol. 'Spontaneous' aggregation using these techniques is rare in healthy individuals, but has been demonstrated in insulin-dependent diabetics free from vascular disease (Krzywanek \& Breddan, 1981; Paulsen et al. 1981; Silberbauer et al. 1981).

In recent years newer tests of platelet function have been developed which have paralleled increased understanding of platelet physiology and biochemistry. These relate to the platelet release reaction and prostaglandin metabolism. B-Thromboglobulin and platelet factor 4 are platelet-specific proteins stored in the $\alpha$-granules of platelets (Moore et al. 1975; Niewiarowski et al. 1977). They are released during platelet aggregation to a variety of agonists (Holmsen \& Weiss, 1979). The most abundant protein is B-thromboglobulin (molecular weight 35000) and since it has a plasma half-life of $100 \mathrm{~min}$ (Dawes et al. 1978) it is a useful indicator of enhanced in vivo platelet activation and release reaction.

Levels of B-thromboglobulin have been found to be elevated in many studies of diabetes with and without vascular disease (Burrows et al. 1978; Preston et al. 1978; Mathews et al. 1979; Borsey et al. 1980; Betteridge et al. 1981; Davi et al. 1982) but not all (Campbell et al. 1977; Fritschi et al. 1984; Van de Knaap et al. 1985). However, the interpretation of these findings is open to conjecture. Do raised levels of B-thromboglobulin truly reflect in vivo platelet activation and release or are they a consequence of increased release following activation (Kubisz et al. 1984) or increased levels of B-thromboglobulin in diabetic platelets (Brooks et al. 1983)? Van Oost et al. $(1982,1984)$ have provided evidence that increased levels are related to increased release due to increased sensitivity of diabetic platelets to stimulation, with their finding of decreased 
platelet density in diabetes with retinopathy. Platelets are less dense after secretion of their $\alpha$-granules.

In vivo platelet activation has also been assessed by measuring platelet survival with radiolabelled platelets, and shortened platelet survival has been demonstrated in diabetics with and without complications (Abrahamsen, 1968; Dassin et al. 1978; Jones et al. 1981; Winocour et al. 1982). This is consistent with the finding of increased numbers of circulating young platelets in diabetics (Karpatkin, 1972; Garg et al. 1972; Colwell et al. 1977).

Increased awareness of the critical importance of prostaglandin metabolism in platelets and arterial wall has stimulated many studies in diabetes. In platelets,

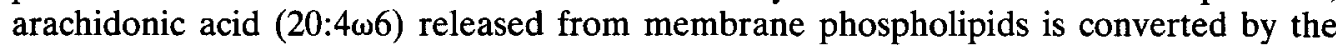
cyclooxygenase enzyme system to unstable endoperoxides. These compounds may be further metabolized by thromboxane synthetase ( $E C$ 5.3.99.5) to yield thromboxane $\mathrm{A}_{2}$, a powerful pro-aggregatory and vasoactive substance, which is the arachidonic acid metabolite that mediates platelet aggregation and the release reaction (Hamburg et al. 1975). On the other hand, in arterial intima, the major arachidonic acid metabolite is prostacyclin which is the most potent of the naturally occurring prostaglandins in inhibiting platelet aggregation (Moncada et al. 1976).

The early work of Halushka et al. (1977) and Chase et al. (1979) demonstrated increased activity of the prostaglandin pathway in platelets from diabetics, and subsequently indirect measures of thromboxane $A_{2}$ in diabetic platelets using malondialdehyde, a stable product of endoperoxide conversion to thromboxane $\mathrm{A}_{2}$ (Stuart et al. 1979; Betteridge et al. 1981) and thromboxane $\mathrm{B}_{2}$, the stable hydrolysis product of thromboxane $\mathrm{A}_{2}$ (Ziboh et al. 1979; Butkus et al. 1980) have been performed in diabetic patients. These studies and studies in experimental animals (Subbiah \& Deitemeyer, 1980; Johnson et al. 1980; Karpen et al. 1982) have provided evidence of increased thromboxane $\mathrm{A}_{2}$ synthesis in diabetic platelets.

It remains to be determined which of the metabolic abnormalities of diabetes mellitus are important in relation to the observed alterations in platelet function. An obvious candidate would be hyperglycaemia, possibly acting through post-transcriptional modification of platelet proteins by glycosylation. However, although some cross-sectional studies have reported significant correlations between aspects of platelet function and glycaemic control (assessed as the prevailing blood glucose level or by measurement of glycosylated haemoglobin as an indication of long-term glycaemic control) (Peterson et al. 1977; Halushka et al. 1981a,b; Dettori et al. 1983), this has by no means been a universal finding (Burrows et al. 1978; Mathews et al. 1979; Betteridge et al. 1981; Davi et al. 1982). Equally conflicting results have been obtained in prospective studies of diabetic subjects in which the effect of improved glycaemic control (mainly using subcutaneous insulin infusion or the artificial pancreas) on platelet function has been assessed. Some studies have demonstrated potentially beneficial alterations in platelet function (Peterson et al. 1977; Giugliano et al. 1982; Juhan et al. 1982; McDonald et al. 1982; Voisin et al. 1983) but others have shown no change (Rosove et al. 1984; Delamothe \& Betteridge, 1985) or an increase in platelet sensitivity (Jackson et al. 1984).

Other plasma factors affecting platelets in diabetes mellitus could be plasma lipids and lipoproteins, and in a study of forty-nine diabetic subjects significant correlations were found between ß-thromboglobulin levels and very-low-density lipoprotein (VLDL), triglyceride and low-density lipoprotein (LDL)-cholesterol (Betteridge et al. 1981). Lipoproteins may indirectly affect platelet function by altering vascular endothelial cell function. Recent experimental work has suggested that lipoproteins (VLDL) obtained from diabetic animals may be more toxic to cultured endothelial cells than lipoproteins 
from control animals. This effect, which may be due to increased lipid peroxide levels in diabetes, was reversed by insulin treatment (Arbogast et al. 1982).

The original observation of Harrison et al. (1978) of decreased prostacyclin production in aortic rings taken from streptozotocin-diabetic rats has been confirmed and extended by other workers (Harrison et al. 1980; Silberbauer et al. 1980; Rogers \& Larkins, 1981; El Tahir et al. 1982; Karpen et al. 1982; Kern \& Engerman, 1984). The reduction in vascular prostacyclin production appears to be related to the duration of the diabetic state and is restored by insulin therapy. Serum from diabetic patients inhibited prostacyclin production in cultured human endothelial cells (Paton et al. 1982; Patel et al. 1983; Aanderud et al. 1985). The nature of the inhibitory factor or factors in the diabetic serum is not understood but a likely contender would be lipid peroxides which are known to be increased in diabetics (Nishigaki et al. 1981; Higuchi, 1982) and to be potent inhibitors of prostacyclin synthesis (Salmon et al. 1978). In support of this Karpen et al. (1982) found that vitamin $E$ treatment of experimental diabetic rats reduced plasma lipid peroxide levels and restored prostacyclin production to normal. In addition to the findings that vascular prostacyclin production may be decreased in diabetes it has been shown that platelets obtained from diabetic subjects show diminished sensitivity to the antiaggregatory effects of prostacyclin in vitro (Betteridge et al. 1982; Onodera et al. 1982; Jones et al. 1985).

\section{Platelet function in hyperlipoproteinaemia}

In recent years there has been an increased interest in lipid-platelet interactions (Anon., 1980). Platelet-derived growth factor has important effects on LDL receptor activity (Chait $e$ al. 1980) and it is known that platelets which are unable to synthesize cholesterol de novo possess specific LDL receptors (Aviram \& Brook, 1983). Lipoproteins have important actions on arterial-wall prostacyclin production, LDL and VLDL inhibiting and high-density lipoprotein (HDL) stimulating production (Nordøy et al. 1978).

Early platelet studies in hyperlipoproteinaemic subjects measured platelet aggregation in vitro. These studies (Nordøy \& Rodset, 1971; Carvalho et al. 1974) which showed increased aggregation in response to adrenaline, collagen and ADP in hypercholesterolaemic patients have been confirmed by others (Tremoli et al. 1979; Shastri et al. 1980). Some studies (Molinas et al. 1981) have not demonstrated increased platelet aggregation in hypercholesterolaemia, probably due to technical considerations and differences in patient selection. However, a recent large study of 150 patients with hypercholesterolaemia confirmed increased sensitivity of platelets to collagen, ADP and adrenaline (Tremoli et al. 1984). In addition, total and LDL-cholesterol concentrations appeared to influence platelet sensitivity to adrenaline and to a lesser extent ADP in a normal male population (Hassall et al. 1983).

Support for a relation between hypercholesterolaemia and platelet function has come from the application of newer techniques. Zahavi et al. (1981) measured plasma platelet-specific protein levels in a large group of hypercholesterolaemic patients and found high levels of $B$-thromboglobulin and platelet factor 4 compared with age- and sex-matched controls. In this study an extra control group of patients with known peripheral vascular disease was included. This group had higher levels of platelet-specific proteins than healthy controls but lower levels than hypercholesterolaemic subjects. Platelet malondialdehyde formation as a measure of thromboxane synthesis was also assessed in this study and found to be increased (Zahavi et al. 1981). Other studies have found increased thromboxane $A_{2}$ synthesis (assessed as the more stable thromboxane 
$B_{2}$ ) in platelets from hypercholesterolaemic subjects (Tremoli et al. 1979, 1984; Strano et al. 1982).

The relation between hypertriglyceridaemia and platelet function is not so clear. Carvalho et al. (1974) found no evidence of increased platelet aggregation in patients with hypertriglyceridaemia and Shastri $e t$ al. (1980) found increased aggregation but only to adrenaline. In a normal male population Hassall et al. (1983) found little relation between VLDL and platelet sensitivity except for a reduced adrenaline response in subjects in the lowest quintile for VLDL concentrations. However, platelet-specific proteins showed highly significant elevations in hypertriglyceridaemic individuals studied by Zahavi et al. (1981) as did malondialdehyde formation but Strano et al. (1982) could not demonstrate increased thromboxane $\mathrm{B}_{2}$ production. On the other hand, Joist $e t$ al. (1979) found shorter template bleeding times in sixteen patients with hypertriglyceridaemia and Curtis et al. (1984), using the impedence aggregometer which measures platelet function in whole blood, demonstrated increased platelet sensitivity to collagen and decreased sensitivity to prostacyclin in both hypercholesterolaemic and hypertriglyceridaemic individuals.

Confirmation of direct effects of lipids and lipoproteins on platelet function have come from in vitro experiments. Shattil et al. (1975) incubated normal platelets with 'cholesterol-rich' liposomes which led to a substantial increase in platelet cholesterol concentration, particularly in the platelet membrane. This led to enhanced sensitivity to adrenaline and ADP. Conversely, cholesterol-depleted platelets showed reduced sensitivity to aggregating agonists. The same authors (Shattil et al. 1977) found that platelets from hypercholesterolaemic individuals had a higher membrane cholesterol: phospholipid ratio and other workers demonstrated elevated free cholesterol in platelets from similar subjects (Miettinen, 1974). In addition Shattil \& Cooper (1976) described increased platelet membrane microviscosity following incubation of platelets with 'cholesterol-rich' liposomes and Sinha et al. (1977) found an impaired response of the membrane-associated enzyme adenylate cyclase ( $E C$ 4.6.1.1) to the stimulating effect of various agents including prostaglandin $\mathrm{E}$, as shown by reduced production of cyclic AMP. More recent studies have demonstrated that increases in the cholesterol:phospholipid ratio of platelets resulted in increased thrombin-induced aggregation and increased liberation of arachidonate (Wörner \& Patscheke, 1980). Jakubowski et al. (1980) failed to show an increase in the cholesterol:phospholipid ratio of platelets obtained from hypercholesterolaemic subjects compared with age- and sex-matched controls, but cholesterol levels were lower than those in the subjects studied by Shattil et al. (1977). However, Jakubowski et al. (1980) did show that hypercholesterolaemic platelets had an impaired ability to accumulate cyclic AMP compared with controls when challenged with prostacyclin or prostaglandins $D_{2}$ and $E_{1}$. The failure to demonstrate quantitative changes in the cholesterol:phospholipid ratio of the whole platelets does not rule out changes in membrane lipids as this may be masked if only total lipids are studied (Shattil et al. 1977). The impaired ability of hypercholesterolaemic platelets to accumulate cyclic AMP in response to prostacyclin does not appear to be explained by changes in either affinity or number of prostacyclin receptors, although the platelets do show reduced sensitivity to the antiaggregatory effects of prostacyclin (Colli et al. 1983).

Stuart et al. (1980) have studied the influence of cholesterol loading on platelet arachidonic acid metabolism. In cholesterol-enriched platelets (pre-labelled with $\left[{ }^{14} \mathrm{C}\right]$ arachidonic acid) thrombin stimulation led to the release of more arachidonic acid from pre-labelled platelet phospholipid. Subsequent conversion of arachidonic acid to thromboxane was also enhanced. It is possible that cholesterol-induced increases in platelet membrane microviscosity may affect the activity of phospholipase $A_{2}$ which is 
responsible for the release of arachidonic acid (Stuart et al. 1980). In a recent study Tandon et al. (1983) have shown that the number of thrombin receptors increased with increasing membrane viscosity while binding affinity decreased. Receptor number appeared to be the principal determinant of platelet responsiveness; however coupling between occupied receptor and bioresponse was unaffected by changes in membrane viscosity (Tandon et al. 1983).

Some studies have examined the acute effects of lipoproteins on platelet function in vitro. Aviram \& Brook (1983) incubated purified lipoproteins with gel-filtered platelets and showed that VLDL as well as LDL increased thrombin-induced platelet aggregation. Furthermore Beitz et al. (1983) demonstrated a dose-dependent stimulation of malondialdehyde formation from prostaglandin $\mathrm{H}_{2}$ by LDL whereas no effect was seen with albumin or HDL. Platelet function has been studied in patients with familial hypercholesterolaemia undergoing treatment with plasma exchange. Brook et al. (1983) found that platelet $\left[{ }^{14} \mathrm{C}\right]$ serotonin release and platelet aggregation in response to adrenaline and ADP paralleled changes in LDL levels, falling after plasma exchange and returning to pre-exchange values after $10 \mathrm{~d}$. This study provides further evidence for LDL effects on platelet function in vivo.

\section{Fatty acids, platelets and thrombosis}

An important cornerstone of therapy in diabetes and hyperlipoproteinaemia, diseases associated with increased risk of premature vascular disease, is diet. In addition, in Western countries the population as a whole is encouraged to eat a more-prudent diet. An important component of this advice concerns a reduction in the amount of dietary fat which typically provides around $40 \%$ of the energy intake (about $120 \mathrm{~g}$ fat $/ \mathrm{d}$ ). In particular a reduction in saturated fat from dairy products and meat is advocated with partial replacement with polyunsaturated fat. With increasing knowledge of the importance of fatty acids as precursors of platelet and arterial endothelial cell prostaglandins and thromboxanes, attention has focused on the different series of polyunsaturated fatty acids in relation to their effects on platelet and vessel-wall metabolism (Goodnight $e t$ al. 1982; Sanders, 1983, 1985; Hornstra, 1985).

\section{Saturated fatty acids}

In the 1960s the thrombotic potential of saturated fatty acids was demonstrated in experiments in which long-chain fatty acids such as stearic acid (18:0) were added to whole blood or washed platelets and various models of thrombogenesis. However, polyunsaturated fatty acids had little or no effect in these experiments (Connor, 1962; Connor et al. 1963; Hoak et al. 1963, 1964, 1967; Kopper, 1963; Haslam, 1964; Mahadevan et al. 1966). Subsequent chronic feeding experiments in experimental animals demonstrated that diets rich in saturated fat predisposed to thrombus formation in response to a variety of stimuli and that platelets showed increased aggregation to thrombin (Nordøy et al. 1968; Renaud et al. 1970, 1979; Hornstra, 1975; McGregor et al. 1980).

\section{Polyunsaturated fatty acids}

Prostaglandins and thromboxanes in platelets and vessel walls are produced from certain C20 polyunsaturated fatty acids with varying degrees of unsaturation, the most abundant of these acids in human tissue being arachidonic acid (20:4w6) (Crawford, 1983). It is possible therefore that dietary manipulation of the precursor fatty acids might influence prostaglandin metabolism and the interactions of platelets with the vessel wall as other polyunsaturated fatty acids may act as substrates for prostaglandin synthesis 
(Willis, 1981) and interfere in other ways with platelet and vessel wall arachidonic acid metabolism (Goodnight et al. 1982; Sanders, 1983).

\section{$\omega 6$ fatty acids}

Linoleic acid $(18: 2 \omega 6)$ is generally the most abundant dietary polyunsaturated fatty acid and its absolute requirement (approximately $1 \%$ of energy intake) is well established (Rivers \& Frankel, 1981). On the other hand, the dietary content of longer-chain derivatives such as arachidonic acid is low, and linoleic acid is converted to dihomo$\gamma$-linoleic acid (20:3w6) and arachidonic acid in liver and other tissues (Willis, 1981) but not in platelet membranes in response to dietary supplementation. Thus feeding experimental animals and man on a diet containing maize oil led to increased platelet membrane linoleic acid but a decrease or no change in arachidonic acid (McGregor et al. 1980; Brox et al. 1981; Galli et al. 1981). It is possible that linoleic acid competes with arachidonic acid for esterification sites in membrane phospholipids or that there is failure of conversion of linoleic acid to longer-chain derivatives.

Along with these changes in platelet membrane fatty acids, decreases have been observed in platelet aggregation and adhesion in both experimental animals and man (Fleischman et al. 1975; Agradi et al. 1978; Brox et al. 1981) together with increased platelet life-span (Mustard \& Murphy, 1962) and a reduction in heparin thrombin clotting time (O'Brien et al. 1976). However, there is general agreement that bleeding time is not prolonged (Hornstra et al. 1973; O'Brien et al. 1976; Brox et al. 1981). The mechanisms by which dietary supplementation with linoleic acid affects platelet function are not completely clear but may include a reduction in thromboxane $A_{2}$ synthesis (Agradi et al. 1978; Brox et al. 1981; Galli et al. 1981) and increased platelet cyclic AMP (McGregor \& Renaud, 1978). Several studies have attempted to assess aortic prostacyclin production in experimental animals and in cultured human umbilical endothelial cells and on the whole they have demonstrated reduced spontaneous and stimulated prostacyclin output (de Deckere et al. 1979; Nordøy et al. 1979; ten Hoor et al. 1980; Galli et al. 1981; Spector et al. 1981).

Dihomo- $\gamma$-linoleic acid $(20: 3 \omega 6)$ has been given as the ethyl or methyl ester in experimental studies because of the very small amounts in natural fats and oils. In these experiments it was possible to enrich platelets and endothelial cells with the fatty acid and this was associated with a decreased content of arachidonic acid and linoleic acid (Oelz et al. 1976; Stone et al. 1980; Willis, 1981). However, the results obtained in terms of platelet behaviour have not been fully consistent. Dihomo- $\gamma$-linoleic acid inhibited platelet aggregation when added to platelet-rich plasma (Willis et al. 1974) and platelet aggregation to ADP was inhibited after volunteers took a single dose (Kernoff et al. 1977). More chronic feeding experiments have shown no change or decreased platelet aggregation (Willis et al. 1974; Oelz et al. 1976) and no change in bleeding time (Kernoff et al. 1977). Dihomo- $\gamma$-linoleic acid is the precursor of the series- 1 prostaglandins but incorporation of the fatty acid into platelets does not lead to $\mathrm{PGE}_{1}$ formation (Needleman et al. 1980). In addition incorporation into endothelial cells results in decreased prostaglandin production (Nordøy et al. 1979).

\section{$\omega 3$ fatty acids}

Although linolenic acid $(18: 3 \omega 3)$ can be desaturated and elongated to eicosapentaenoic acid $(20: 5 \omega 3)$ in most tissues but not platelets it is theoretically possible that diets rich in linolenic acid (e.g. linseed oil) could enrich platelets and arterial endothelial cells with eicosapentaenoic acid. Eicosapentaenoic acid rose from $0 \cdot 1$ to $3.4 \%$ in liver and serum lipids of rats fed up to $4 \%$ of energy as methyl linolenate but in humans linseed oil 
appears to have little effect on eicosapentaenoic acid levels (Dyerberg et al. 1980; Sanders \& Younger, 1981). Although rats fed on linolenic acid showed reduced platelet sensitivity (ten Hoor et al. 1980), no effect was observed on platelet adhesion or bleeding time in patients with coronary artery disease (Borchgrevink et al. 1965).

More interest has focused on eicosapentaenoic acid which is a more potent inhibitor of in vitro platelet aggregation than linolenic acid (Jakubowksi \& Ardlie, 1978; Gruglewski et al. 1979). This stems from the observations of Bang and Dyerberg who linked the diet of Greenland Eskimos which contained large amounts of $\omega 3$ polyunsaturated acids (Bang et al. 1976) with the prolonged bleeding time, reduced platelet aggregation and reduced incidence of vascular disease in this population (Dyerberg \& Bang, 1979). This diet is associated with high amounts of eicosapentaenoic acid in plasma and platelets with a corresponding reduction of both linoleic and arachidonic acid (Dyerberg et al. 1975; Dyerberg \& Bang, 1979). Subsequent studies in volunteers given various fish oils have shown similar changes in platelet fatty acids (for review, see Goodnight et al. 1982; Sanders, 1983, 1985) with a marked increase in the ratio of 20:5 $33 / 20: 4 \omega 6$ and changes in platelet function. For instance, Seiss et al. (1980) observed reductions in platelet aggregation and thromboxane synthesis in healthy men fed on a mackerel diet (500-800 g) for 1 week. Japanese fishermen who regularly consume about $250 \mathrm{~g}$ fish daily showed reduced platelet sensitivity to ADP compared with a control group of Japanese farmers (Hirai et al. 1980).

Other studies have examined the effects of a variety of fish-oil supplements on platelet aggregation in both human volunteers and experimental animals. The findings are not wholly consistent but several studies have shown reduced sensitivity to the aggregating effects of ADP (Sanders et al. 1981; Bradlow et al. 1983; Lorenz et al. 1983; Nagakawa et al. 1983) and collagen (Brox et al. 1981; Goodnight et al. 1981; Bradlow et al. 1983; Lorenz et al. 1983; Nagakawa et al. 1983; Sanders \& Hochland, 1983). Furthermore, Hay et al. (1982) demonstrated significant falls in B-thromboglobulin and platelet factor 4 in thirteen patients with ischaemic heart disease given a daily supplement of $20 \mathrm{ml}$ Maxepa

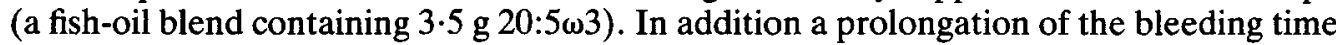
is a near-universal finding in response to fish-oil supplementation (for review, see Goodnight et al. 1982; Sanders, 1985). This is probably related to a reduction of platelet thromboxane $\mathbf{A}_{2}$ formation (measured as thromboxane $\mathbf{B}_{2}$ ) following fish-oil administration (Seiss et al. 1980; Brox et al. 1981; Bradlow et al. 1983; Fischer \& Weber, 1983; Lorenz et al. 1983; Sanders \& Hochland, 1983) as thromboxane is an important vasoconstrictor following vascular injury (Butler et al. 1982). An alternative explanation for the prolonged bleeding time may be that fish oil has a greater effect on platelet thromboxane $\mathrm{A}_{2}$ formation than on vessel-wall prostacyclin production. In support of this, in vivo prostacyclin production, assessed as its major urinary metabolite 2,3-dinor-6keto-PGI $\mathrm{PI}_{1 \alpha}$ was found to be unaltered in volunteers given eicosapentaenoic acid $(10 \mathrm{~g} / \mathrm{d})$ for 4 weeks as Maxepa oil, but serum thromboxane $B_{2}$ was markedly decreased (Knapp \& Fitzgerald, 1984).

The initial hypothesis to explain the effects of eicosapentaenoic acid on platelet prostaglandin production was that the fatty acid would be a substrate for the cyclooxygenase and thromboxane synthetase enzyme systems with the production of thromboxane $A_{3}$, a weak platelet-aggregating substance. On the other hand in arterial wall the major metabolite of eicosapentaenoic acid would be prostacyclin $\mathrm{I}_{3}$ which retains its anti-platelet-aggregating properties. However, although production of the series-3 prostaglandins has been demonstrated following fish-oil supplementation in humans (Fischer \& Weber, 1983, 1984), only small amounts are formed as eicosapentaenoic acid is a poor substrate for cyclooxygenase (Needleman et al. 1979; Smith et al. 1979). It is 
likely that the major effect of eicosapentaenoic acid is on arachidonic acid metabolism. Arachidonic acid is displaced from membrane phospholipid so reducing its availability as substrate for cyclooxygenase, and eicosapentaenoic acid acts as a competitive inhibitor for this enzyme (Culp et al. 1979; Needleman et al. 1979).

To the clinician faced with making dietary recommendations to patients known to be at risk from premature vascular disease, the $\omega 3$ fatty acids would appear to have exciting potential. Long-term prospective studies need to be carried out in this area to determine whether $\omega 3$ fatty acid dietary supplements can help reverse abnormal platelet function in diabetes mellitus and hyperlipoproteinaemia and eventually reduce the incidence of vascular disease without serious adverse effects. Traditionally the lower saturated-fat diet recommended for these patients has involved substitution with polyunsaturated fatty acids of the $\omega 6$ series, principally linoleic acid. In a study of platelet reactivity in patients with hypertriglyceridaemia treated with a high dietary content of linoleic acid no potentially beneficial changes in platelet behaviour were observed despite significant reductions in plasma lipids and lipoproteins (Boberg et al. 1986). On the other hand, in a group of patients with familial hypercholesterolaemia, dietary supplementation with cod-liver oil as a source of $\omega 3$ fatty acids resulted in reduced platelet aggregation to collagen and a decrease in thrombin-stimulated thromboxane generation against a background of persistently elevated plasma cholesterol levels (Brox et al. 1983).

\section{Conclusions}

There is evidence to implicate platelets in the development of atherosclerosis as well as the thrombotic complications in diseased arteries. Some population groups (particularly those with diabetes mellitus and hyperlipoproteinaemia) known to be at risk from premature vascular disease have evidence of abnormal platelet function. Dietary therapy is a cornerstone of treatment in these conditions and it would seem appropriate to consider the possible role of $\omega 3$ fatty acids in diabetes and hyperlipoproteinaemia in view of the potential benefit on platelet function.

\section{REFERENCES}

Aanderud, S., Krane, H. \& Nordøy, A. (1985). Diabetologia 28, 641-644.

Abrahamsen, A. F. (1968). Scandinavian Journal of Haematology, Suppl. 3, 7-53.

Agradi, E., Tremoli, E., Colombo, C. \& Galli, C. (1978). Prostaglandins 16, 973-984.

Anon. (1980). Lancet i, 464-465.

Arbogast, B. W., Lee, G. M. \& Raymond, T. L. (1982). Diabetes 31, 593-599.

Aviram, M. \& Brook, J. G. (1983). Artery 11, 297-305.

Badawi, H., El-Sawy, M. \& Mikhail, M. (1970). Angiology 21, 511-519.

Bang, H. O. \& Dyerberg, J. (1972). Acta Medica Scandinavica 192, 85-94.

Bang, H. O., Dyerberg, J. \& Hyørne, N. (1976). Acta Medica Scandinavica 200, 69-73.

Bang, H. O., Dyerberg, J. \& Nielsen, A. (1971). Lancet i, 1143-1146.

Beitz, J., Panse, M. \& Forster, W. (1983). Prostaglandins, Leukotrienes and Medicine 10, 443-448.

Betteridge, D. J. (1987). In Diabetes and the Heart, pp. 81-119 [K. G. Taylor, editor]. Tunbridge Wells: Castle House.

Betteridge, D. J., El Tahir, K. E. H., Reckless, J. P. D. \& Williams, K. I. (1982). European Journal of Clinical Investigation 12, 395-398.

Betteridge, D. J., Zahavi, J., Jones, N. A. G., Shine, B., Kakkar, V. V. \& Galton, D. J. (1981). European Journal of Clinical Investigation 11, 273-277.

Bloodworth, J. M. Jr \& Molitor, D. L. (1965). Investigative Ophthalmology 4, 1037-1048.

Boberg, M., Gustafsson, G. \& Vessby, B. (1986). European Journal of Clinical Investigation 16, $28-34$.

Borchgrevink, F., Berg, K. J., Skjaeggestad, O., Skaga, E. \& Stormorken, H. (1965). Lancet ii, $980-981$.

Born, G. V. R. (1962). Nature 194, 927-929. 
Borsey, D. Q., Dawes, J., Fraser, D. M., Prowse, C. V., Elton, R. A. \& Clarke, B. F. (1980). Diabetologia 18, 353-357.

Bowen-Pope, D. F. \& Ross, R. (1984). Clinics in Endocrinology and Metabolism 13, 191-205.

Bradlow, B. A., Chetty, N., van der Westhuyzen, J., Mendelsohn, D. \& Gibson, J. E. (1983). Thrombosis Research 29, 561-568.

Brook, G., Winterstein, G. \& Aviram, M. (1983). Clinical Science 64, 637-642.

Brooks, A. M. V. M., Hussein, S., Chesterman, C. N., Martin, J. F., Alford, F. P. \& Penington, D. E. (1983). Thrombosis and Haemostasis 49, 123-127.

Brox, J. H., Killie, J. E., Gunnes, S. \& Nordøy, A. (1981). Thrombosis and Haemostasis 46, 604-611.

Brox, J. H., Killie, J. E., Osterud, B., Holme, S. \& Nordøy, A. (1983). Acta Medica Scandinavica 213, 137-144.

Burrows, A. W., Chavin, S. \& Hockaday, T. D. R. (1978). Lancet i, 235-237.

Butkus, A., Skrinska, V. A. \& Schumaker, O. P. (1980). Thrombosis Research 19, 211-223.

Butler, K. D., Maguire, E. D., Smith, J. R., Turnbull, A. A., Wallis, R. B. \& White, A. M. (1982). Thrombosis and Haemostasis 47, 46-82.

Campbell, I. W., Dawes, J., Fraser, D. M., Pepper, D. S., Clarke, B. F., Duncan, L. F. J. \& Cash, J. D. (1977). Diabetes 26, 1175-1177.

Carvalho, A. C. A., Colman, R. W. \& Lees, R. S. (1974). New England Journal of Medicine 290, $434-438$.

Cella, G., Zahavi, J., De Haas, H. A. \& Kakkar, V. V. (1979). British Journal of Haematology 43, $127-136$.

Chait, A., Ross, R., Albers, J. J. \& Bierman, E. L. (1980). Proceedings of the National Academy of Sciences, USA 77, 4084-4088.

Chase, H. P., Williams, R. L. \& Dupont, J. (1979). Journal of Paediatrics 94, 185-189.

Christensen, P. E., Schmidt, H., Bang, H. O., Andersen, V., Jordal, B. \& Jensen, O. (1953). Acta Medica Scandinavica 144, 430-433.

Colli, S., Lombroso, M., Maderna, P., Tremoli, E. \& Nicosia, S. (1983). Biochemical Pharmacology 32, 1989-1993.

Colwell, J. A., Halushka, P. V., Sarki, K. E. \& Sagel, J. (1978). Medical Clinics of North America 62, 753-766.

Colwell, J. A., Sagel, J., Crook, L., Chambers, A. \& Laimins, M. (1977). Metabolism 28, 279-285.

Colwell, J. A., Winocour, P. D. \& Halushka, P. V. (1983). Diabetes 32, Suppl. 2, 14-19.

Connor, W. E. (1962). Journal of Clinical Investigation 41, 1199-1205.

Connor, W. E., Hoak, J. C. \& Warner, E. D. (1963). Journal of Clinical Investigation 42, 860-866.

Constantinides, P. (1966). Journal of Atherosclerosis Research 6, 1-17.

Corbella, E., Miragliotta, G., Masper, R., Villa, S., Bini, A., Chiumello, G. \& de Gaetano, G. (1979). Haemostasis 8, 30-37.

Crawford, M. A. (1983). British Medical Bulletin 39, 210-213.

Culp, B. R., Titus, B. G. \& Lands, W. E. M. (1979). Prostaglandins and Medicine 3, 269-278.

Curtis, L. D., Jones, R. J., Machin, S. J. \& Betteridge, D. J. (1984). European Journal of Clinical Investigation 14, 37.

Dassin, E., Najean, Y., Poirier, O., Passa, P. H. \& Bensoussan, D. (1978). Thrombosis and Haemostasis 40, 83-88.

Davi, G., Rini, G. B., Averna, M., Novo, S., Di Fede, G., Mattina, A., Notarbartolo, A. \& Strano, A. (1982). Haemostasis 12, 275-281.

Davies, M. J. \& Thomas, T. (1981). Philosophical Transactions of the Royal Society of London 294B, $225-229$.

Davis, J. W., Hartman, C. R., Davis, R. F., Kyner, J. L., Lewis, H. D. Jr \& Phillips, P. E. (1982). Acta Haematologica 67, 222-224.

Dawes, J., Smith, R. C. \& Pepper, D. S. (1978). Thrombosis Research 12, 851-881.

de Deckere, E. A. M., Nutgeren, D. H. \& ten Hoor, F. (1979). Prostaglandins 17, 947-955.

Delamothe, A. P. \& Betteridge, D. J. (1985). Diabetic Medicine 2, 319A.

Dettori, A. G., Quintavalla, R. \& Poli, T. (1983). Acta Haematologica 96, 65-66.

Duguid, J. B. (1946). Journal of Pathology 58, 207-212.

Dyerberg, J. \& Bang, H. O. (1979). Lancet i, 433-435.

Dyerberg, J., Bang, H. O. \& Aagaard, O. (1980). Lancet i, 199.

Dyerberg, J., Bang, H. O. \& Hjørne, N. (1975). American Journal of Clinical Nutrition 28, 958-966.

Dyerberg, J., Bang, H. O., Stoffersen, E., Moncada, S. \& Vane, J. R. (1978). Lancet ii, 117-119.

El-Maraghi, N. \& Genton, E. (1980). Circulation 62, 936-944.

El Tahir, K. E. H., Williams, K. I. \& Betteridge, D. J. (1982). Prostaglandins, Leukotrienes and Medicine 8, $429-435$. 
Faggiotto, A. \& Ross, R. (1984), Arteriosclerosis 4, 341-356.

Faggiotto, A., Ross, R. \& Harker, L. (1984). Arteriosclerosis 4, 323-340.

Fischer, S. \& Weber, P. C. (1983). Biochemical and Biophysical Research Communications 116, 1091-1099.

Fischer, S. \& Weber, P. C. (1984). Nature 307, 165-168.

Fleischman, A. I., Justice, D., Bierenbaum, M. L., Stier, A. \& Sullivan, A. (1975). Journal of Nutrition 105, 1286-1290.

Fritschi, J., Christie, M., Lämmle, B., Marbet, G. A., Berger, W. \& Duckert, F. (1984). Thrombosis and Haemostasis 52, 236-239.

Galli, C., Agradi, E., Petroni, A. \& Tremoli, E. (1981). Lipids 16, 165-172.

Garg, S. K., Lackner, H. \& Karpatkin, S. (1972). Annals of Internal Medicine 77, 361-369.

Giugliano, D., Misso, L., Tirelli, A., Coppola, L., Di Pinto, P. \& Torrella, R. (1982). Diabetologia $23,545$.

Goodnight, S. H., Harris, W. S. \& Connor, W. E. (1981). Blood 58, 880-885.

Goodnight, S. H. , Harris, W. S., Connor, W. E. \& Illingworth, D. R. (1982). Arteriosclerosis 2, 87-113.

Gruglewski, R. J., Salmon, J. A., Ubatuba, F. B., Weatherly, B. C., Moncada, S. \& Vane, J. R. (1979). Prostaglandins 18, 453-478.

Haerem, J. W. (1972). Atherosclerosis 15, 199-213.

Halushka, P. V., Lurie, D. \& Colwell, J. A. (1977). New England Journal of Medicine 297, 1306-1310.

Halushka, P. V., Mayfield, R., Wohltmann, H. J., Rogers, R. C., Goldberg, A. K., McCoy, S. A., Loadholt, C. A. \& Colwell, J. A. (1981a). Diabetes, Suppl. 2, 44-48.

Halushka, P. V., Roger, R. C., Loadholt, C. B. \& Colwell. J. A. (1981b). Journal of Laboratory and Clinical Medicine 97, 87-96.

Hamburg, M., Svensson, J. \& Samuelsson, B. (1975). Proceedings of the National Academy of Sciences, USA 72, 2994-2998.

Handin, R. I., McDonough, M. \& Lesch, M. (1978). Journal of Laboratory and Clinical Medicine 9, $340-349$.

Harker, L. A. \& Ross, R. (1979). Seminars in Thrombosis and Haemostasis 5, 274-292.

Harrison, H. E., Reece, A. H. \& Johnson, M. (1978). Life Sciences 23, 351-356.

Harrison, H. E., Reece, A. H. \& Johnson, M. (1980). Diabetologia 18, 65-68.

Haslam, R. J. (1964). Nature 202, 765-768.

Hassall, D. G., Forrest, L. A., Bruckdorfer, R., Marenah, C. B., Turner, P., Cortese, C., Miller, N. E. \& Lewis, B. (1983). Arteriosclerosis 3, 332-338.

Hay, C. R. M., Durber, A. P. \& Saynor, R. (1982). Lancet i, 1269-1272.

Heath, H., Brigden, W. D., Canever, J. V., Pollock, J., Hunter, P. R., Kelsey, J. \& Bloom, A. (1971). Diabetologia 7, 308-315.

Hellem, A. J. (1971). Acta Medica Scandinavica 190, 291-295.

Higuchi, Y. (1982). Acta Medica Okayama 36, 165-175.

Hirai, A., Hamazaki, T., Terano, T., Nishikawa, T., Tamura, Y., Kumagai, A. \& Sajiki, J. (1980). Lancet ii, $1132-1133$.

Hoak, J. C., Connor, W. E., Eckstein, J. W. \& Warner, E. D. (1964). Journal of Laboratory and Clinical Medicine 3, 791-800.

Hoak, J. C., Poole, J. C. F. \& Robinson, D. S. (1963). American Journal of Pathology 43, 987-993.

Hoak, J. C., Warner, E. D. \& Connor, W. E. (1967). Circulation Research 20, 11-17.

Holmsen, H. \& Weiss, H. J. (1979). Annual Review of Medicine 30, 119-134.

Hornstra, G. (1975). In The Role of Fats in Human Nutrition, pp. 303-330 [A. J. Vergroesen, editor]. London: Academic Press.

Hornstra, G. (1985). Proceedings of the Nutrition Society 44, 371-378.

Hornstra, G., Chait, A., Karvonen, M. J., Lewis, B., Turpeinen, O. \& Vergroesen, A. J. (1973). Lancet i, 1155-1157.

Ishibashi, T., Tanika, K. \& Tanigueki, Y. (1981). Diabetes 30, 601-606.

Jackson, C. A., Greaves, M., Boulton, A. J. M., Ward, J. D. \& Preston, F. E. (1984). Clinical Science 67, $551-555$.

Jakubowski, J. A. \& Ardlie, N. G. (1978). Atherosclerosis 31, 335-344.

Jakubowksi, P. J., Ardlie, N. G. \& Nestel, P. J. (1980). Prostaglandins and Medicine 5, 457-467.

Janka, H. U., Standl, E., Schramm, W. \& Mehnert, H. (1983). Diabetes 32, Suppl., 47-53.

Jarrett, R. J., Keen, H. \& Chakrabarti, R. (1982). In Complications of Diabetes, pp. 179-204 (H. Keen and R. J. Jarrett, editors]. London: Edward Arnold. 
Johnson, M., Reece, A. H. \& Harrison, H. E. (1980). In Advances in Prostaglandin and Thromboxane Research, vol 8, pp. 1283-1286 [B. Samuelsson, P. W. Ramwell and R. Paoletti, editors]. New York: Raven Press.

Joist, J. H., Baker, K. \& Schoenfeld, G. (1979). Thrombosis Research 15, 95-108.

Jones, R. J., Delamothe, A. P., Curtis, L. D., Machin, S. J. \& Betteridge, D. J. (1985). Diabetic Medicine 2, 105-109.

Jones, R. L., Paradise, C. \& Peterson, C. M. (1981). Diabetes 30, 486-489.

Juhan, I., Vague, P., Buonocore, M., Moulin, J. P., Jouve, R. \& Vialettes, B. (1982). Lancet i, $535-537$.

Karpatkin, S. (1972). Annals of the New York Academy of Sciences 201, 262-279.

Karpen, C. W., Pritchards, K. A. Jr, Merola, A. J. \& Panaganamala, R. V. (1982). Prostaglandins, Leukotrienes and Medicine 8, 93-103.

Kern, T. S. \& Engerman, R. L. (1984). Diabetes 33, 846-850.

Kernoff, P. B. A., Willis, A. L., Stone, K. J., Davies, J. A. \& McNicol, G. P. (1977). British Medical Journal ii, 1441-1444.

Knapp, H. R. \& Fitzgerald, G. A. (1984). Symposium on n-3 fatty acids, July 1984, University of Reading. Potters Bar: International Association of Fish Meal Manufacturers.

Kopper, P. H. (1963). Nature 200, 133-134.

Kromann, N. \& Green, A. (1980). Acta Medica Scandinavica 208, 401-406.

Krzywanek, H. M. \& Breddan, K. (1981). Hormone and Metabolic Research 11, Suppl., 11-14.

Kubisz, P., Arabi, A., Holan, J. \& Cronberg, C. (1984). Haemostasis 14, 347-353.

Lorenz, R., Spengler, U., Fischer, S., Duhm, J. \& Weber, P. C. (1983). Circulation 67, 504-511.

Ludlam, C. A., Bolton, A. E., Moore, S. \& Cash, J. D. (1975). Lancet ii, 259-260.

McDonald, J. W., Dupre, J., Rodger, N. W., Champion, M. C., Webb, C. D. \& Ali, M. (1982). Thrombosis Research 28, 705-712.

McGregor, L., Morazain, R. \& Renaud, S. (1980). Laboratory Investigation 43, 438-442.

McGregor, L. \& Renaud, S. (1978). Thrombosis Research 12, 921-927.

Mahadevan, V., Singh, M. H. \& Lundberg, W. O. (1966). Proceedings of the Society for Experimental Biology and Medicine 121, 82-85.

Mathews, J. H., O'Connor, J. F., Hearnshaw, J. R. \& Wood, J. K. (1979), Scandinavian Journal of Haematology 23, 421-426.

Mayne, E. G., Bridges, J. M. \& Weaver, J. A. (1970). Diabetologia 6, 436-440.

Miettinen, T. A. (1974). Thrombosis Research 4, Suppl., 41-47.

Molinas, F. C., Drucker, E., Korduch, L., Reynolds, M. A. \& Finkielman, S. (1981). Thrombosis Research 22, 427-435.

Moncada, S., Gruglewski, R. J., Bunting, S. \& Vane, J. R. (1976). Nature 263, 663-665.

Moore, S., Pepper, D. S. \& Cash, J. D. (1975). Biochimica et Biophysica Acta 379, 360-369.

Mustard, J. F. \& Murphy, E. A. (1962). British Medical Journal i, 1651-1654.

Mustard, J. F., Packham, M. A. \& Kinlough-Rathbone, R. L. (1983). In Atherosclerosis: Mechanisms and Approaches to Therapy, pp. $29-43$ [N. E. Miller, editor]. New York: Raven Press.

Nagakawa, Y., Orimo, H., Harasawa, M., Morita, I., Yashiro, K. \& Murota, S. (1983). Atherosclerosis 47, $71-75$.

Needleman, P., Raz, A., Minkes, M. S., Ferrendelli, J. A. \& Sprecher, H. A. (1979). Proceedings of the National Academy of Sciences, USA 76, 944-948.

Needleman, P., Whitaker, M. O., Wyche, A., Watters, K., Sprecher, H. \& Raz, A. (1980). Prostaglandins 19, 165-181.

Niewiarowski, S., Budzynski, A. Z. \& Lipinski, B. (1977). Blood 49, 635-644.

Nishigaki, I., Hagihara, M., Tsunekawa, H., Maseki, M. \& Yagi, K. (1981). Biochemical Medicine 25, 373-378.

Nordøy, A., Hamlin, J. T., Chandler, A. B. \& Newland, H. (1968). Scandinavian Journal of Haematology 5, 458-473.

Nordøy, A. \& Rodset, J. M. (1971). Acta Medica Scandinavica 189, 385-389.

Nordøy, A., Svensson, B. \& Hoak, J. C. (1978). Circulation Research 43, 527-534.

Nordøy, A., Svensson, B. \& Hoak, J. C. (1979). European Journal of Clinical Investigation 9, 5-10.

O'Brien, J. R., Etherington, M. D., Jamieson, S., Vergroesen, A. J. \& ten Hoor, S. (1976). Lancet il, 995-996.

Oelz, O., Seyberth, H. W., Knapp, H. R., Sweetman, B. J. \& Oates, J. A. (1976). Biochimica et Biophysica Acta 431, 268-277.

Onodera, H., Hirata, R. \& Sugaware, H. (1982). Tohoku Journal of Experimental Medicine 137, $423-428$. 
Packham, M. A. \& Mustard, J. F. (1986). Seminars in Haematology 23, 8-26.

Patel, M. K., Evans, C. E. \& McEvoy, F. A. (1983). Bioscience Reports 3, 33-60.

Paton, R. C., Guillot, R., Passa, P. \& Canivet, J. (1982). Diabète et Metabolisme 8, 323-328.

Paulsen, E. P., McChung, N. M. \& Sabio, H. (1981). Hormone and Metabolic Research 11, Suppl., 15-21.

Petersen, H. D. \& Gormsen, J. (1978). Acta Medica Scandinavica 203, 125-130.

Peterson, C. M., Jones, R. L., Koenig, R. J., Melvin, E. T. \& Lehrman, M. L. (1977). Annals of Internal Medicine 86, 425-429.

Preston, F. E., Ward, J. D., Marcola, B. H., Porter, N. R., Timperley, W. R. \& O'Malley, B. C. (1978). Lancet i, 238-240.

Renaud, S., Kinlough, R. L. \& Mustard, J. F. (1970). Laboratory Investigation 22, 339-343.

Renaud, S., Morazain, R., McGregor, L. \& Baudier, F. (1979). Haemostasis 8, 234-251.

Rivers, J. P. W. \& Frankel, T. L. (1981). British Medical Bulletin 37, 59-64.

Rogers, S. P. \& Larkins, R. G. (1981). Diabetes 30, 935-939.

Rosove, M. H., Frank, H. J. L. \& Harwig, M. S. (1984). Diabetes Care 7, 174-179.

Ross, R., Faggiotto, A., Bowen-Pope, D. \& Raines, E. (1984). Circulation 70, Suppl. 3, 77-82.

Ross, R. \& Glomset, J. (1976). New England Journal of Medicine 295, 369-377.

Ross, R., Glomset, J., Kariya, B. \& Harker, L. (1974). Proceedings of the National Academy of Sciences, USA 71, 1207-1210.

Ross, R. \& Vogel A. (1978). Cell 14, 203-210.

Sagel, J., Colwell, J. A., Crook, L. \& Laimins, M. (1975). Annals of Internal Medicine 82, 733-738.

Salmon, J. A., Smith, D. R., Flower, R. J., Moncada, S. \& Vane, J. R. (1978). Biochimica et Biophysica Acta $523,250-262$.

Sanders, T. A. B. (1983). Clinical Science 65, 343-350.

Sanders, T. A. B. (1985). Proceedings of the Nutrition Society 44, 391-397.

Sanders, T. A. B. \& Hochland, M. (1983). British Journal of Nutrition 50, 521-529.

Sanders, T. A. B., Vickers, M. \& Haines, A. P. (1981). Clinical Science 61, 317-324.

Sanders, T. A. B. \& Younger, K. M. (1981). British Journal of Nutrition 45, 613-616.

Seiss, W., Scherer, B., Bohlig, B., Roth, P., Kurzman, I. \& Weber, P. C. (1980). Lancet i, 441-444.

Shastri, K. M., Carvalho, A. C. A. \& Lees, R. S. (1980). Journal of Lipid Research 21, 467-472.

Shattil, S. J., Anaya-Galindo, R., Bennett, J., Colman, R. W. \& Cooper, R. A. (1975). Journal of Clinical Investigation 55, 636-643.

Shattil, S. J., Bennet, J. S., Colman, R. W. \& Cooper, R. A. (1977). Journal of Laboratory and Clinical Medicine 89, 341-353.

Shattil, S. J. \& Cooper, R. A. (1976). Biochemistry 15, 4832-4837.

Shaw, S., Pegrum, G. D., Wolff, S. \& Ashton, W. L. (1967). Journal of Clinical Pathology 20, 845-847.

Silberbauer, K., Clopath, P., Sinzinger, H. \& Schernthaner, G. (1980). Artery 8, 30-36.

Silberbauer, K., Schernthaner, G., Sinzinger, H. \& Freyler, H. (1981). Atherosclerosis 40, 81-90.

Sinha, A. K., Shattil, S. J. \& Colman, R. W. (1977). Journal of Biological Chemistry 252, 3310-3314.

Smith, D. R., Weatherly, B. C., Salmon, J. A., Ubatuba, F. B., Gryglewki, R. J. \& Moncada, S. (1979). Prostaglandins 18, 423-438.

Spector, A. A., Kaduce, T. L., Hoak, J. C. \& Fry, G. L. (1981). Journal of Clinical Investigation 65, 1003-1012.

Stewart, M., Douglas, J. T., Lowe, G. D. O., Forbes, C. D. \& Prentice, C. R. M. (1983). Thrombosis and Haemostasis 50, 373.

Stone, K. J., Willis, A. L., Hart, M., Kirtland, S. J., Kernoff, P. B. A. \& McNicol, G. P. (1980). Lipids 14, 174-180.

Strano, A., Davi, G., Averna, M., Rini, G. B., Novo, S., Mattina, A. \& Notarbartolo, A. (1982). Thrombosis and Haemostasis 48, 18-20.

Stuart, M. J., Elrad, H., Graeber, J. E., Hakanson, D. O., Sunderji, S. G. \& Barvinchak, M. D. (1979). Journal of Laboratory and Clinical Medicine 94, 12-17.

Stuart, M. J., Gerrard, J. M. \& White, J. G. (1980). New England Journal of Medicine 302, 6-10.

Subbiah, M. T. R. \& Deitemeyer, D. (1980). Biochemical Medicine 23, 231-235.

Tandon, N., Harmon, J. T., Rodbard, D. \& Jamieson, G. A. (1983). Journal of Biological Chemistry 258, 11840-11845.

ten Hoor, F., de Deckere, E. A. M., Haddeman, E., Hornstra, G. \& Quadt, J. F. A. (1980). Advances in Prostaglandin and Thromboxane Research 6, 1771-1781.

Timperly, W. R., Preston, F. E. \& Ward, J. D. (1974). Lancet i, 952-956. 
Timperly, W. R., Preston, F. E. \& Ward, J. D. (1974). Lancet i, 952-956.

Timperly, W. R., Ward, J. D., Preston, F. E., Duckworth, T. \& O’Malley, B. C. (1975). Diabetologia 11, 379-380.

Tremoli, E., Maderna, P., Colli, S., Morazzoni, G., Sirtori, M. \& Sirtori, C. R. (1984). European Journal of Clinical Investigation 14, 329-333.

Tremoli, E., Maderna, P., Sirtori, M. \& Sirtori, C. R. (1979). Haemostasis 8, 47-53.

Valdorf-Hansen, F. (1967). Danish Medical Bulletin 14, 244-248.

Van de Knaap, J. H., de Boer, A. C., Pannebakker, M. A. G., van Heerde, W. \& den Ottolander, G. J. H. (1985). Thrombosis and Haemostasis 53, 118-121.

Van Oost, B. A., Timmermans, A. P. M. \& Sixma, J. J. (1984). Blood 63, 482-485.

Van Oost, B. A., Veldhuyzen, B. F. E., van Houwelingen, H. C., Timmermans, A. P. M. \& Sixma, J. J. (1982). Thrombosis and Haemostasis 48, 289-293.

Voisin, P. J., Rouselle, D., Streiff, F., Debry, G., Stoltz, J. F. \& Drouin, P. (1983). Metabolism 32, $138-141$.

Willis, A. L. (1981). Nutrition Reviews 38, 289-391.

Willis, A. L., Comai, K., Kuhn, D. C. \& Paulsrud, J. (1974). Prostaglandins 8, 509-519.

Winocour, P. D., Cattaneo, M., Somers, D., Richardson, M., Kinlough-Rathbone, R. L. \& Mustard, J. F. (1982). Arteriosclerosis 2, 458-466.

Woolf, N. (1983). In Atherosclerosis: Mechanisms and Approaches to Therapy, pp. 1-27 [N. E. Miller, editor]. New York: Raven Press.

Wörner, P. \& Patscheke, H. (1980). Thrombosis Research 18, 439-451.

Wu, K. K. \& Hoak, J. C. (1974). Lancet ii, 924-926.

Zahavi, J., Betteridge, D. J., Jones, N. A. G., Galton, D. J. \& Kakkar, V. V. (1981). American Journal of Medicine 70, 59-64.

Zahavi, J. \& Zahavi, M. (1985). Thrombosis and Haemostasis 53, 105-109.

Ziboh, V. A., Maruta, H., Lords, J., Cagle, W. D. \& Lucky, W. (1979). European Journal of Clinical Investigation 9, 223-228. 